\title{
GREBEG MAULUD DALAM REPRESENTASI BUSANA DAN MOTIF BATIK DI KERATON YOGYAKARTA
}

\author{
Renta Vulkanita Hasan *)
}

\begin{abstract}
Culture growing in Indonesia and overseas intrinsically dynamic. Nature of culture as a result of human creativity is always moving and displacement. When his journey to the vibrant place anyway, culture is likely to mix with the native culture which then grow and develop into a new culture. Culture is a strong factor that affects the mindset. Over time, society has a way of looking at the world deal, behave, and interact with each other. In other words, they have their own color and pattern of the deal while making rules in social life. Yogyakarta in Java, which is known as one of the cultural centers of Java development, especially ritual Grebeg Maulud. Ritual Grebeg Maulud over time reflecting the constantly changing movement of social change, culture, politics, economics and society in his day. Ritual is a means of connecting Grebeg Maulud transcendental between man and God (Manunggaling Kawula-Gusti) and guidance from the teachings of the holy book (Islam). But this time Grebeg Maulud also has another function, namely as a spectacle. This suggests a cultural shift from the sacred to the profane. Batik as a dress code in the Carnival celebrations Grebeg Maulud is one reflection of the existence of culture in Yogyakarta Palace. The use of batik in a ritual procession Grebeg Maulud is a tradition that continues to this day. Batik palace is considered one of the symbols of the existence of power relations by creating a specific motive for a particular class. Dynamism of culture led to the use of batik is not only a marker of power relations, but also as an exciting treat for the fashion show at the Carnival lasts Grebeg Maulud.
\end{abstract}

Keyword: Grebeg, Maulud, representations, clothing, batik, palace, Yogyakarta

\section{Pendahuluan}

\section{Grebeg dan Masyarakat}

Masyarakat terlihat mulai memadati sepanjang lingkar Alun-alun Utara, Kota Yogyakarta, khususnya di sekitar masjid agung Yogyakarta. Ada yang membawa kamera, mulai dari jenis pocket sampai DSLR (Digital Single Lens Refleks) untuk mengabadikan kegiatan yang sebentar lagi dimulai. Ada juga yang hanya sekedar membawa payung untuk melindungi dirinya dari terik matahari. Masyarakat berdatangan untuk menyaksikan jalannya prosesi Grebeg Maulud, salah satu tradisi yang dilakukan oleh Keraton Yogyakarta sebagai kegiatan ritual untuk memperingati kelahiran Nabi Muhammad SAW.

Istilah Grebeg tidaklah asing bagi masyarakat Daerah Istimewa Yogyakarta dan

\footnotetext{
* Renta Vulkanita Hasan (voelca@gmail.com), Staf Pengajar Program Studi Televisi dan Film, Fakultas Sastra, Universitas Jember
} 
sekitarnya, bahkan masyarakat juga menyebutnya dengan istilah Sekaten. Setiap kali kegiatan itu digelar, masyarakat mendapat Masyarakat seakan memanjakan mata mereka dengan hiburan-hiburan yang tidak selalu ada setiap hari. Terlebih bagi masyarakat pendatang di Yogyakarta, baik yang menetap maupun yang hanya sekedar rekreasi. ${ }^{2}$ Masyarakat memiliki kecenderungan menginterpretasi keindahan yang tampak oleh mata. Penginderaan-penginderaan tersebut akhirnya menimbulkan kegembiraan, terlepas dari kegunaan sesuatu yang tampak tersebut. Aristoteles menyatakan bahwa semua pengetahuan manusia berasal dari suatu kecenderungan dasar dalam kodrat manusia yang menampakkan diri dalam aksi-aksi dan reaksi manusia paling elementer (Cassirer, 1987: 5).

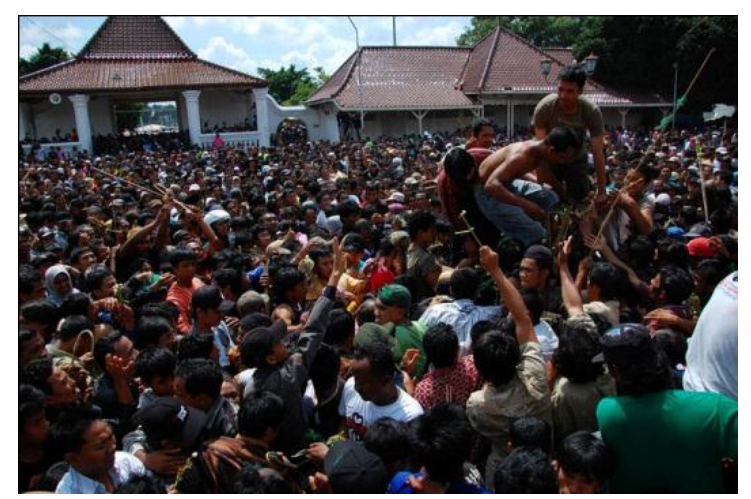

Gambar 1. Suasana masyarakat yang menyaksikan Arakarakan dan memperebutkan Gunungan di sekitar Masjid Agung, Alun-alun Utara, Kota Yogyakarta. (Dokumentasi: Humanika, 2010).

Antusiasme masyarakat dalam menyambut Grebeg Maulud dari tahun ke tahun tampaknya tidak pernah surut. Hal ini terbukti dengan berjubalnya masyarakat di sepanjang jalan yang akan dilalui oleh rombongan arak-arakan gunungan. Banyak juga warga dari luar kota yang telah datang di lokasi sejak semalam atau bahkan sehari sebelumnya. Mereka datang dari beberapa kota, seperti Magelang, Klaten, Purworejo, hiburan "gratis" yang bermacam-macam. Mulai aneka kuliner sampai arak-arakan. ${ }^{1}$ gunungan yang dibawa oleh prajurit kerato dan Temanggung untuk sekedar menonton atau memperebutkan gunungan dengan kepercayaannya masing-masing. ${ }^{3}$

Arak-arakan prajurit Keraton memiliki daya tarik bagi penonton. Daya tarik tersebut berupa tampilan beragam busana yang dikenakan, baik dari segi model atau pola busana, warna, motif, maupun aksesoris. Bagi penonton, prajurit-prajurit tersebut bagaikan peragawan yang sedang memperagakan busana "istimewa" sebagai lambang eksistensi budaya di Keraton Yogyakarta.

\section{Tradisi Grebeg di Keraton Yogyakarta}

Keraton Yogyakarta memiliki tradisi penyelenggaraan Grebeg sebanyak tiga kali dalam setahun. Upacara Grebeg tersebut meliputi Grebeg Syawal, Grebeg Maulud, dan Grebeg Besar. Grebeg Syawal dilaksanakan sebagai bentuk peringatan akan selesainya bulan puasa atau bulan Ramadhan dan hadirnya bulan Syawal. Grebeg Maulud dilaksanakan sebagai bentuk peringatan kelahiran Nabi Muhammad SAW. Grebeg Besar dilaksanakan sebagai bentuk peringatan bulan Dzulhijah. Pelaksanaan Upacara Grebeg dianggap sebagai wujud atau simbol kemurahan dan perlindungan raja terhadap kawulanya. Simbol itu diwujudkan dengan perarakan gunungan yang dikawal kesatuankesatuan prajurit keraton yang disebut bregada. Keraton Yogyakarta memiliki 10 kesatuan prajurit yang mengiringi perarakan gunungan itu, yakni Prajurit Wirabraja, Daeng, Nyutra, Mantrijero, Patang Puluh, Bugis, Ketanggung, Jagakarya, Prawiratama, dan Surakarsa. Pada masa lalu ada bregada atau kesatuan prajurit lain, yakni Sumaatmaja, Jager, dan Langenastra. ${ }^{4}$ 


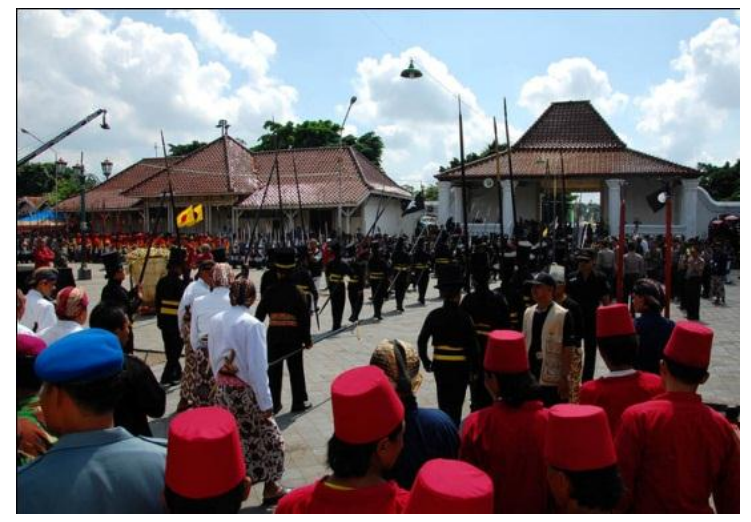

Gambar 2. Prajurit atau Bregada Keraton Yogyakarta pada Prosesi Grebeg Maulud (Dokumentasi: Humanika, 2010)

\section{Pembahasan}

\section{Identitas dalam Selembar Kain Batik}

Batik memang bukan satu-satunya kain motif yang terdapat di Indonesia maupun mancanegara. Indonesia memiliki bermacammacam kain motif, seperti tenun, jumputan, maupun tapis. Tenun merupakan kain motif yang banyak diproduksi di beberapa tempat, antara lain: Pedan (Klaten, Jawa Tengah), Gianyar (Bali), Garut (Jawa Barat). Lalu jumputan banyak diproduksi di beberapa tempat, salah satunya: Palembang (Sumatera Selatan), sedangkan tapis banyak diproduksi di wilayah Lampung (Sumatera).

Kita sering mendengar istilah Batik Pekalongan, Batik Mataraman, Batik Pesisiran, dan Batik Pedalaman. Belum lama ini, kita juga mendengar istilah Batik Magelang atau Magelangan dan lain sebagainya. Pengistilahan atau penamaan tersebut biasanya diberikan sesuai tempat batik tersebut diproduksi. Akhirnya penamaan tersebut menjadi identitas sebuah batik yang sudah terekam dalam asumsi masyarakat. Selembar kain batik memang dapat dijadikan sebagai identitas suatu tempat atau wilayah. Apalagi jika wilayah tersebut memiliki ikon- ikon tertentu yang merepresentasikan sejarah, hasil bumi, maupun produksi yang terdapat di wilayah tersebut.

Motif Parang misalnya, dalam kajian sejarah batik dijelaskan bahwa motif ini pertama diaplikasikan sebagai motif batik adalah di wilayah Mataram, yang saat ini dikenal dengan wilayah Yogyakarta dan Surakarta (Anas, 1997: 64). Motif Parang diciptakan dan diaplikasikan ke dalam motif batik sebagai penanda identitas seorang raja yang dikenakan pada saat-saat tertentu, seperti upacara. Motif Parang merupakan deformasi sebuah tebing yang di atasnya berdiri seekor burung besar yang melambangkan eksistensi seorang raja yang merupakan perwakilan dari Tuhan dalam konteks Mikrokosmos (Manunggaling KawulaGusti). Selain motif Parang, ada lagi motif Semen, yang di dalamnya terepresentasikan ajaran Astha Bratha. ${ }^{5}$

\section{Batik sebagai Busana di Keraton Yogyakarta}

Batik merupakan kumpulan beberapa pola yang membentuk motif serta disajikan dengan teknik penggambaran yang meliputi aspek bentuk, ruang, irama, dan warna. Pengertian batik yang lain adalah pekerjaan menciptakan motif pada kain dengan cara menorehkan lilin malam panas di atas kain, baik yang sudah digambari motif maupun belum. Motif-motif yang biasa diterapkan pada kain sangat beragam jumlahnya. Secara garis besar terdapat dua jenis motif, yaitu geometris dan nongeometris. Motif-motif yang tergolong ke dalam geometris antara lain: Ceplokan, Parang, dan Lereng, sedangkan yang tergolong nongeometris antara lain: Semen dan Buketan.

Batik merupakan salah satu kesenian Istana yang dianggap penting sebagai sarana ritual, di samping untuk memenuhi kebutuhan 
sandang atau busana dan penanda kedudukan sosial. Busana dapat dikatakan sebagai penanda yang mewakili hal-hal tertentu, seperti kepribadian, status sosial, dan karakter keseluruhan si pemakai (Danesi, 2011: 205). Busana tidak sekedar sebagai penutup badan dengan tujuan perlindungan, tetapi dia (busana) juga merupakan sistem tanda yang saling terkait dengan sistem-sistem tanda lainnya dalam masyarakat. Melalui penanda tersebut, dapat terkirim pesan akan sikap maupun status sosial seseorang.

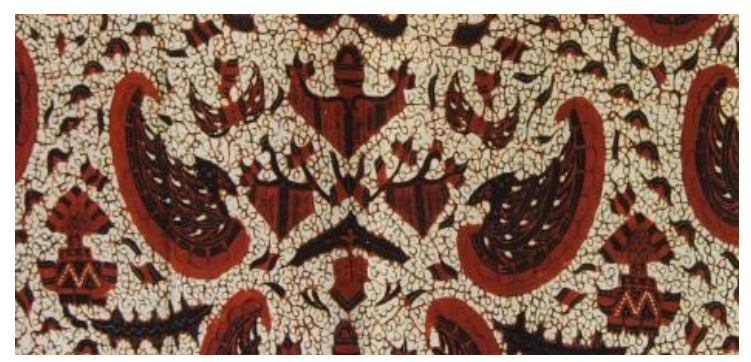

Gambar 3. Motif batik Semen Rama

Setiap motif batik memiliki arti dan simbol tertentu. Motif Parang, misalnya, motif tersebut merupakan motif larangan dan pakaian keprabon yang hanya boleh dikenakan raja, putra mahkota dan permaisuri (Ricklefs, 1974: 276). Kepercayaan akan terciptanya suasana religius magis dari pancaran ragam hias batik membuat para bangsawan pada masa itu lebih mengutamakan busana dengan beberapa ragam hias batik yang mengandung arti simbolik.

\section{Batik dalam Prosesi Grebeg Maulud di Keraton Yogyakarta}

Beragam busana adat Keraton Yogyakarta yang menggunakan batik sebagai dress code ditampilkan dalam perayaan Grebeg Maulud di Keraton Yogyakarta. Seperti halnya prajurit-prajurit (bregada) Keraton Yogyakarta yang terbagi-bagi dalam beberapa kesatuan, seperti Wirabraja, Daeng, Nyutra, Mantrijero, Patang Puluh, Bugis, Ketanggung, Jagakarya, Prawiratama, dan Surakarsa, mengenakan busana keprajuritan wilayah masing-masing. Manggalayuda Prajurit Keraton yang dalam hal ini adalah GBPH. Yudaningrat, juga mengenakan busana kebesaran berupa kuluk (penutup kepala), ageman (setelan busana berbahan beludru disulam benang emas), dan dodot (kain panjang bermotif batik). ${ }^{6}$ Selain itu, para kerabat dan abdi dalem keraton juga mengenakan busana adat Keraton Yogyakarta.

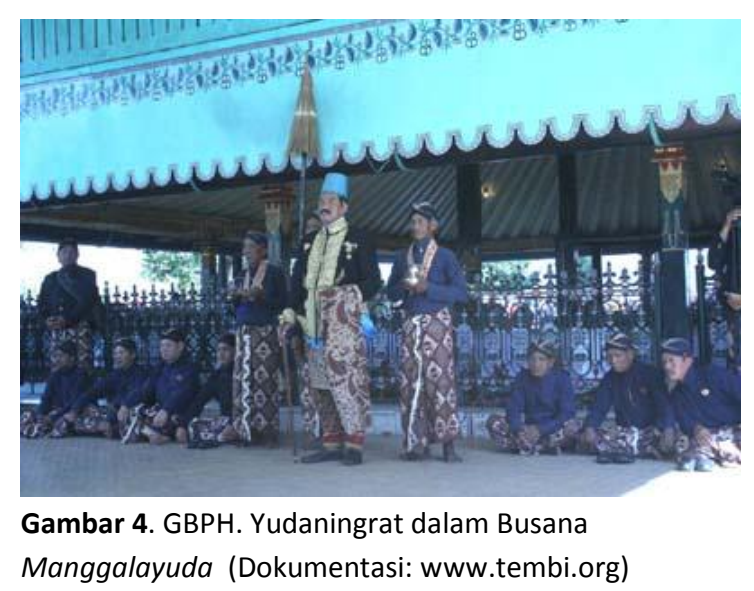

Sepanjang perayaan Grebeg Maulud di Keraton Yogyakarta, penggunaan busana adat merupakan salah satu bagian yang selalu ditampilkan. Kerabat dan abdi dalem Keraton menganggap pentingnya penggunaan busana adat dalam setiap prosesi. ${ }^{7}$ Seperti halnya penggunaan busana dengan motif batik tertentu merupakan simbol, identitas, dan harapan si pemakai. Lain halnya bagi masyarakat umum, penggunaan busana adat oleh kerabat dan abdi dalem Keraton Yogyakarta menjadi salah satu suguhan menarik bagi mereka. Ketika arak-arakan prajurit digelar, masyarakat seakan melihat peragaan busana adat yang luar biasa. Mereka bahkan ada yang mengatakan arak-arakan itu adalah sebuah fashion show. ${ }^{8}$ Persepsi itu 
muncul sebagai akibat perubahan kondisi sosial masyarakat yang terjadi sejak busana tersebut masih aktif digunakan sampai hari ini, yang penggunaannya hanya dapat disaksikan dalam perayaan seperti Grebeg Maulud. Fashion menyebabkan perubahan yang cepat dalam gaya berpakaian seseorang karena alasan historis, psikologis, dan sosiologis.

\section{Penutup}

Asumsi masyarakat ketika menyaksikan Kirab Grebeg Maulud pada saat ini lebih cenderung kepada hiburan dan seni yang sensasional. Arak-arakan gunungan yang diikuti prajurit Keraton dari berbagai kesatuan (bregada), lalu ritual rayahan atau rebutan sesaji gunungan oleh penonton merupakan pertunjukan yang terbentuk akibat sensasi yang ditimbulkan oleh penontonnya. Masyarakat juga cenderung mengapresiasi motif batik pada busana yang digunakan dalam kirab sebagai seni visual dan dress code semata, meskipun dalam prosesi ini batik lebih ditonjolkan sebagai simbol dan sarana penyampaian pesan tertentu.

\section{DAFTAR PUSTAKA}

Anas, Biranul, dkk. 1997. Indonesia Indah: Batik. Jakarta: Yayasan Harapan Kita.

Cassirer, Ernest. 1987. Manusia dan Kebudayaan: Sebuah Esei tentang Manusia. Jakarta: PT. Gramedia.

Danesi, Marcel. 2011. Pesan, Tanda, dan Makna. Yogyakarta: Jalasutra.

De Graaf, H.J. 1990. Puncak Kekuasaan Mataram: Politik Ekspansi Sultan Agung. Jakarta: Pustaka Utama Grafiti dan KITLV.

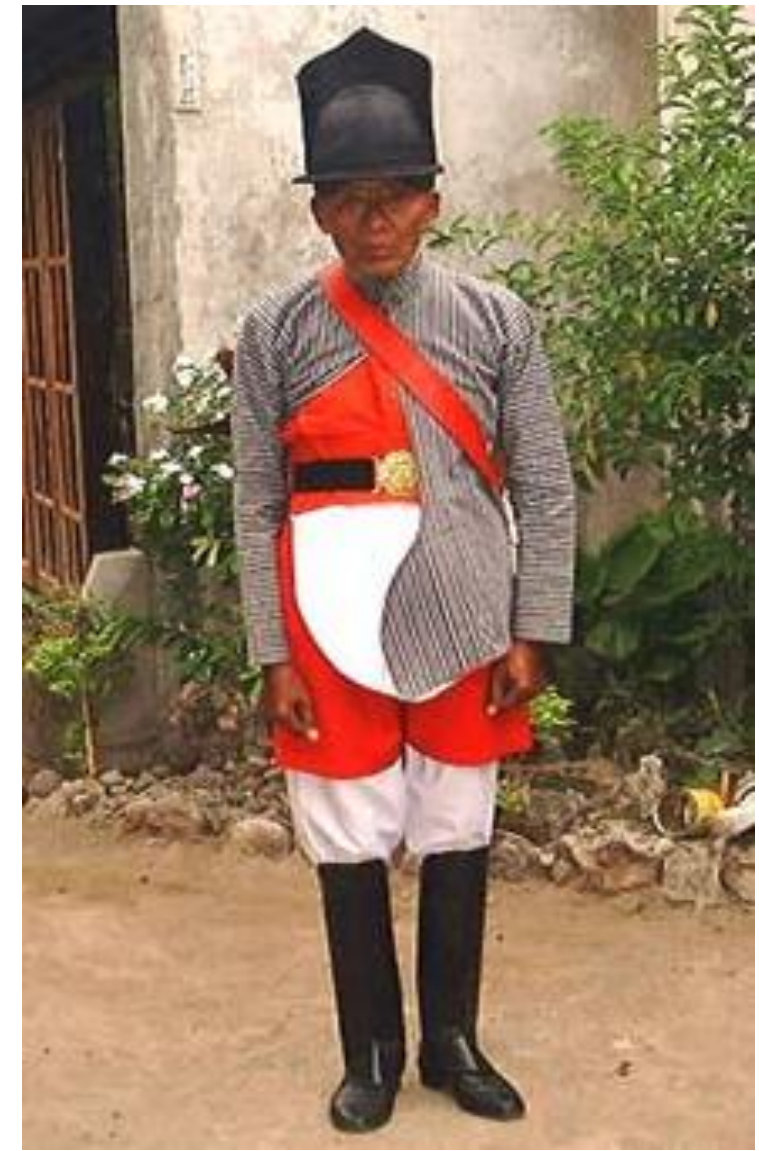

Gambar 5. Prajurit Patang Puluh

(Dokumentasi: www.tembi.org)

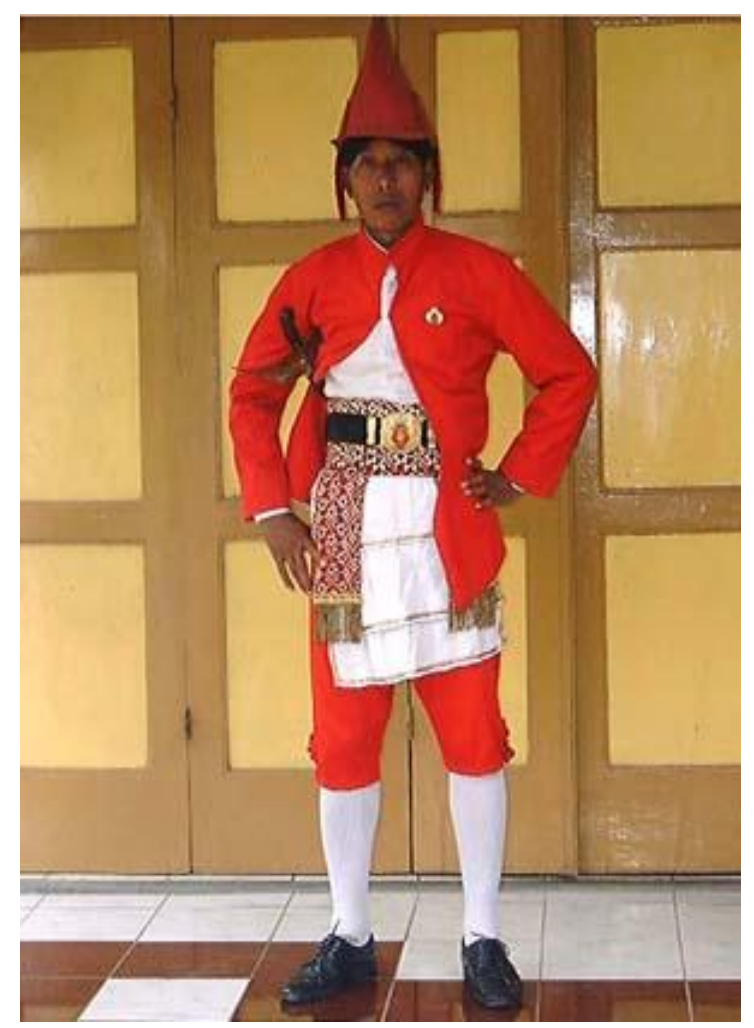

Gambar 6. Prajurit Wirobrodjo

(Dokumentasi: www.tembi.org) 
Djoemena, Nian S. 1990. Ungkapan Sehelai Batik: It's Mistery and Meaning. Jakarta: Djambatan.

\section{Gustami, SP. 2000. Studi Komparatif Gaya Seni} Yogya-Solo. Yogyakarta: Yayasan untuk Indonesia.

Haviland, William A. Antropologi Jilid 2. Terj. R.G. Soekadijo. Jakarta: Penerbit.

Ricklefs, M.C. 1974. Jogjakarta Under Sultan Mangkubumi 1749-1729: A History of The Division of Java. London: Oxford University Press.

\section{CATATAN:}

${ }^{1}$ Gunungan merupakan rangkaian makanan yang disusun sedemikian rupa sehingga membentuk semacam gunung.

${ }^{2}$ Yogyakarta mengenal istilah masyarakat njeron beteng atau sentana dan njaba beteng. Masyarakat njeron beteng atau sentana adalah masyarakat yang tinggal di lingkungan keraton atau tanah-tanah paringan ndalem (tanah pemberian raja), baik yang masih memiliki hubungan kerabat dengan Raja atau tidak ada hubungan dengan Raja. Sedangkan masyarakat njaba beteng adalah masyarakat pendatang atau masyarakat Yogyakarta yang tinggal di luar tembok atau beteng Keraton dan kebanyakan adalah masyarakat pendatang dari luar Yogyakarta.

${ }^{3}$ Ny. Ninik Ebenuchaeri Pakuningrat, kerabat saya yang juga masih memiliki hubungan kerabat dengan Raja di keraton Yogyakarta mengatakan bahwa beliau meyakini uba rampe (isi) dari gunungan tersebut membawa berkah. Demikian juga pendapat dari orang-orang yang pernah saya temui di halaman Masjid Agung Keraton Yogyakarta, bahwa segala cita-cita bisa tercapai apabila berhasil merayah (mengambil dengan cara berebut) isi gunungan tersebut. Kepercayaan demikian disebabkan karena gunungan tersebut dibuat dengan disertai doa-doa yang dilakukan ulama yang ditunjuk keraton. Oleh karena hal-hal semacam itu, maka banyak orang percaya akan keberkahan dari gunungan tersebut (menurut A. Sartono dalam www. tembi. org/.../index-upacara_grebeg_maulud_keraton)
${ }^{4}$ Istilah Garebeg atau Grebeg berasal darikata gerebeg yang berarti suara arak-arakan keluarnya raja dan keluarga dalam upacara tersebut, dengan diiringi para punggawa dan kesatuan prajurit (bregada). Proses keluarnya digambarkan seperti diiringi angin yang berbunyi gerebeg...gerebeg...(A. Sartono dalam www.tembi.org/.../index-

upacara_grebeg_maulud_keraton)

${ }^{5}$ Astha Bratha merupakan, yaitu konsep tentang 8 asas kepemimpinan yang terdapat dalam kakawin Ramayana gubahan Walmiki.

${ }^{6}$ Manggalayudha merupakan pimpinan tertinggi prajurit keraton dan bertanggung jawab dalam pelaksanaan perarakan gunungan hingga sampai ke tempat yang dituju.

${ }^{7}$ Penting dalam hal ini adalah konteks Manunggaling Kawula-Gusti, yaitu sarana penghubung antara manusia dengan Tuhan yang diwujudkan melalui simbol-simbol tertentu. Salah satu simbol tersebut adalah penggunaan busana bermotif batik, seperti motif Semen Rama. Dalam motif Semen Rama terkandung konsep Astha Bratha, yaitu konsep tentang 8 asas kepemimpinan yang terdapat dalam kakawin Ramayana gubahan Walmiki.

${ }^{8}$ Busana adat Keraton Yogyakarta yang dipakai dalam arak-arakan Garebeg Maulud, terutama busana prajurit memiliki pola khusus yang saat ini jarang ditemui dalam aktivitas berbusana sehari-sehari. Masyarakat lantas menganggap hal itu sebagai tontonan yang menarik. Pengartian masyarakat akan segala sesuatu yang nampak dan melekat pada busana tersebut, saat ini lebih kepada fashion. Busana tentara Keraton Yogyakarta dipertunjukkan kembali pada saat ini dalam konteks dan momen yang berbeda. 